\title{
The Effectiveness of Social-Emotional Learning Strategies and Mindful Breathing with Biofeedback on the Reduction of Adolescent Test Anxiety
}

Carolyn McLeod

University of Calgary

Mike Boyes

University of Calgary

\begin{abstract}
Educational programs that incorporate social emotional-learning (SEL) strategies, study skills, and mindful breathing using biofeedback can help adolescents decrease worry and social stress, increase test preparedness self-efficacy, and improve academic performance due to lowered levels of test anxiety. The current study examined the efficacy of a SEL intervention (implemented into a high school psychology course) focused on study skills and mindful breathing and its impact on student attitude and behavioural changes (e.g., test anxiety, self-efficacy), academic performance, and physical changes. A quasi-experimental
\end{abstract}


explanatory mixed methods study conducted at a rural Alberta high school examined preand post-intervention results between two groups of Grades 9-12 students $(N=105)$ with one group receiving the intervention (mindful breathing sessions, emotional regulation techniques, study and test-taking skills, and coping strategies) while the other received regular programming. Quantitative data included a Test Anxiety Survey (TAS), Student Opinion Survey-Short Form (SOS-SF), and reading comprehension (RC) tests to measure attitude and behavioural changes, followed by qualitative data obtained from student semi-structured interviews and focus groups for further interpretation. Quantitative results from repeated-measures (RM) ANOVAs indicated significant increases in self-efficacy for preparation and test-taking, increased academic achievement, decreased worry about future social stress, and increased positive affect. Effect sizes for significant impacts ranged from .45 to .65. Qualitative data indicated that students acquired new SEL strategies to help them handle stressful test situations more effectively. The current study addresses topics of interest to educators (e.g., test anxiety, social emotional learning) with a discussion of applications for extension and development of the program in junior and senior high classrooms.

Keywords: test anxiety, adolescents, social-emotional learning, mindfulness, biofeedback

\section{Résumé}

Les programmes éducatifs qui intègrent des stratégies d'apprentissage socioaffectif, des techniques d'étude et une respiration consciente à l'aide de la rétroaction biologique peuvent aider les adolescents à réduire leurs inquiétudes et leur stress social, à accroître leur capacité à se préparer aux examens et à améliorer leurs résultats scolaires en raison d'un niveau d'anxiété moins élevé lors des examens. L'étude actuelle examine l'efficacité d'une intervention d'apprentissage socioaffectif (mise en œuvre dans un cours de psychologie d'une école secondaire) axée sur les aptitudes à l'étude et la respiration consciente, et son impact sur l'attitude et les changements de comportement des élèves (par exemple, l'anxiété due aux examens, l'autoefficacité), les résultats scolaires et les changements physiques. Une étude quasi expérimentale de méthodes explicatives mixtes menée dans une école secondaire en région rurale de l'Alberta a examiné les résultats pré et post-intervention de deux groupes d'élèves de la $9 \mathrm{e}$ à la $12 \mathrm{e}$ année $(N=105)$. Un groupe a bénéficié de l'intervention (séances de respiration consciente, de techniques de régulation émotionnelle, des aptitudes 
à l'étude et à la préparation aux examens, et de stratégies d'adaptation) tandis que l'autre a reçu le programme régulier. Les données quantitatives comprenaient un sondage pour tester l'anxiété, un sondage abrégé d'opinion auprès des élèves et des tests de compréhension de la lecture pour mesurer les changements d'attitude et de comportement, suivis par des données qualitatives obtenues d'entretiens semi-structurés avec les élèves et de groupes de discussion dirigés pour une interprétation plus approfondie. Les résultats quantitatifs des ANOVA à mesures répétées ont indiqué une augmentation significative de l'autoefficacité pour la préparation et la passation des examens, une augmentation des résultats scolaires, une diminution de l'inquiétude pour un futur stress social et une augmentation d'affects positifs. La taille de l'effet pour les impacts significatifs variait de .45 à .65. Les données qualitatives ont déterminé que les étudiants ont acquis de nouvelles stratégies d'apprentissage socioaffectif pour les aider à gérer plus efficacement le stress des situations d'examens. L'étude actuelle aborde un sujet d'intérêt pour les éducateurs (par exemple, l'anxiété due aux examens, l'apprentissage socioaffectif) avec une discussion des applications pour l'adaptation et le développement du programme dans les classes de premier et deuxième cycles du secondaire.

Mots-clés : l'anxiété due aux examens, adolescents, apprentissage socioaffectif, pleine conscience, rétroaction biologique 


\section{Introduction}

Tests are used ubiquitously in education, often appearing as complicated mazes with discrete solutions requiring careful selection by students looking to move to the next level (Walberg, 2013). With that comes the built-in anxiety around the possibility of failing, rejection from a desired program or pathway, and the subsequent feelings of dejection and defeat. While manageable levels of test anxiety can be motivating, unmanageable levels can debilitate test performance (Wolf \& Smith, 1995). Previous research indicates that $10 \%$ to $40 \%$ of high school students experience some form of test anxiety that impairs their overall academic performance (Von der Embse et al., 2013). Levels of test anxiety are even greater for high-stakes standardized exams, given the increasing competition for university programs (Von Der Embse et al., 2018). Social-emotional learning (SEL) programs and mindfulness techniques using biofeedback have been used to help adolescents control anxiety and improve academic performance (Bradley et al., 2010).

\section{Understanding Test Anxiety}

Test anxiety is broadly defined as the cognitive, emotional, and behavioural responses due to a negative perception of a test or performance (Von der Embse et al., 2013). A student who perceives a test as a threat is often hindered cognitively, leading to a feeling of failure resulting in poorer academic performances, thus reinforcing the negative evaluation the individual has of test situations (Gerwing et al., 2015; Von der Embse et al., 2013; Zeidner, 1998). Excessive anxiety can result in test failure, leading to excessive worrying or rumination (negative cognition) and an inability to concentrate further, resulting in poorer academic achievement (Szafranski et al., 2012). Emotional factors include physiological symptoms such as muscle tension, erratic breathing, increased heart rate, agitation, dizziness, and nausea, all of which can result in a lowered ability to concentrate on the test itself (Szafranski et al., 2012).

Behavioural expressions of test anxiety include procrastination, avoidance, and weaker test-taking and study skills, often resulting in poorer academic performance, further perpetuating the negative spiral (Sasikala \& Karunanidhi, 2010). Students with past histories of poor academic performances may accept failure and thus avoid preparation, accept a low standard of personal performance, and/or exhibit learned helplessness, 
leading to a future-oriented worry involving the perseverance of desired career pathways (Zeidner, 1998). At the other extreme, students who are highly motivated to avoid failure may engage in meticulous test preparation, yet be negatively impacted by worrying thoughts, increasing emotional tension, and unpleasant physiological responses resulting in disrupted studying processes (Zeidner, 1998). Studies have shown that emotionality, a classically conditioned reactive response to a threat, can be counter-conditioned using relaxation, mindfulness, and breathing techniques, along with study skills and SEL strategies to reduce test anxiety and improve test scores (Aritzeta et al., 2017; Bradley et al., 2010).

Heart rate variability and biofeedback. Heart rate variability (HRV) is a physiological measure of time between heart beats in response to stimulation from the vagus nerve, a major branch of the parasympathetic nervous system (Christodoulou \& Black, 2020). The incoherence between heart beats across time reflects a desynchronization between the two autonomic nervous system branches, the sympathetic (fight/flight/ freeze) and parasympathetic (rest/tend/digest) systems, resulting in an overall disruption in neural signals between the prefrontal cortex (and other executive functioning centres of the brain) and heart (Bradley et al., 2010). This desynchronization shows up as erratic, irregular waves (red zone) when the student has the HeartMath (HM) sensor placed on an earlobe and is connected to the Inner Balance app on a phone or tablet.

Alternatively, when the student practices HF breathing (adding positive thoughts of gratitude and appreciation), the sensor reveals regularly spaced repeating sine waves, a measure of coherence between the brain and heart (Bradley et al., 2010). In addition to pumping blood throughout the body, neurological and hormonal information is continually relayed back to the brain (McCraty et al., 2006) with a change to the heart patterns (through breathing management) strongly impacting one's emotional perception (Bradley et al., 2010). By slowing down breathing and bringing HRV into a coherent state (green zone), the individual will achieve a synchronizing of thoughts and emotions, allowing for a deeper cognitive awareness (Bradley et al., 2010). Christodoulou and Black (2020) reviewed 17 empirical studies using mindfulness-based training and HRV metrics, and while finding some variability in both research methods and device accuracy, concluded that a minimum of five minutes of mindful breathing in adult participants led to improved self-regulation and emotional control, which was reflected in observable increases 
in HRV coherence. Utilizing this metric as a biomarker enables users to visualize their progress while learning mindfulness and self-regulation techniques, providing immediate physiological feedback and reinforcement (Christodoulou \& Black, 2020).

\section{Social-Emotional (SEL) Program Effects}

Social-emotional learning (SEL) involves developing skills in goal-setting, managing emotions, making responsible decisions, and forming and maintaining positive relationships (Collaborative for Academic, Social, and Emotional Learning [CASEL], 2020). Researchers utilized the TestEdge skills-based classroom program (a precursor to Smart Brain Wise Heart [SBWH]) to study the effects on test anxiety and overall emotional regulation in Grade 10 students, using measurements from HRV biofeedback, academic test scores, and a student opinion survey (SOS-Q) (Bradley et al., 2010). The researchers concluded that SEL skills combined with biofeedback led to an overall improvement in HRV followed by decreased feelings of test anxiety and increased academic performance (Bradley et al., 2010). Examining SEL programs for the specific factors that lead to their effectiveness is essential - for example, increased self-efficacy, self-esteem, and social awareness while reducing social isolation and anxiety (Coelho \& Sousa, 2017). Self-efficacy, initially described by Albert Bandura (1994), relates to beliefs individuals have about their competencies and the subsequent effect on their level of performance. Self-efficacy can be developed vicariously through social modelling and direct self-mastery of skills and experiences through reinforcement (Bandura, 1994), elements that have been added to this study's intervention program.

A recent meta-analysis involving 50 years of data from 611 studies revealed overall positive effects for SEL interventions in reading and math subjects compared with traditional educational programming and the need for further research into the long-term benefits of SEL programs and academic improvement (Corcoran et al., 2018). Eklund and colleagues (2018) found that many SEL programs lacked important developmental benchmarks, or instructional targets intended for specific age ranges, as well as standardized assessment tools needed for program evaluation and accountability. While some school districts have commenced implementing SEL programing into regular curricula, many either fail to use these programs or use them with poor fidelity (Durlak et al., 2011). 


\section{Current Status of SEL in K-12 Curricula and Research Gaps}

Evidence-based mindfulness programs such MindUp and the Mindfulness Education (ME) program integrated into regular classrooms have resulted in significant improvements in student social emotional awareness (Lawlor, 2014). The Theory of Action (ToA) developed by the CASEL (2020) is now a blueprint for a system-wide SEL implementation in US schools, promoting the adoption of classroom-based SEL strategies with a school-wide or even division-wide approach taken, as is currently underway in the UK and Australia (Oberle et al., 2016). Barriers to a universal implementation include a lack of funding, revising current curricula to include SEL as core competencies taught as mainstream subjects, staff and teacher training, and empirical research to support the shift in this direction (Oberle et al., 2016).

Currently, the wide gap between research into SEL programming and its use in the classroom informs the need for the dissemination of evidence-based practice and proper implementation and program evaluation (Durlak et al., 2011). Additionally, interventions applied by the classroom teacher are more practical and cost-effective, and essentially more efficacious due to the element of teacher-student rapport (Auger, 2011). While there is documentation of the importance of SEL strategies, more research is needed at the classroom level to determine how SEL skills are acquired, the appropriate dosage and developmental stage for use, and how they influence student emotional regulation, overall well-being, and social skills (Meyer, 2016). The current study focused on the delivery of SEL activities within a tailored course; however, components of SEL have also been shown to have positive effects when infused into other areas of the broader curricula (Nickerson et al., 2019).

\section{Study Overview}

One aim of this study was to address the effectiveness of a classroom-based SEL and study skills program combined with heart-focused (HF) breathing (using a self-monitoring biofeedback device) on the reduction of test anxiety in adolescents. HF breathing is a type of mindfulness exercise involving a shift in attentional focus to the breath and heart with a self-induction of positive feelings and gratitude (McCraty et al., 2006). Another aim was to examine the reduction of test anxiety on academic performance. 
An explanatory mixed methods approach was selected to gather quantitative data from test anxiety surveys and an academic test, along with qualitative data gathered from a meta-cognitive student perspective using individual semi-structured interviews and focus groups following the intervention. The mixed methods approach allows for further interpretation of quantitative data, given that the population studied are young adolescents and relatively understudied from a phenomenological perspective (Creswell \& Creswell, 2018). Qualitative follow up provided the researchers with a deeper understanding of the ways in which the skills obtained from the intervention have specifically influenced students' self-efficacy, worry about future social stress, outlook, and test perception and performance.

This study captured the student experience and highlighted the effectiveness of SEL programs and mindful biofeedback on thoughts, feelings, and behaviours related to test anxiety reduction. Providing the participants with opportunities to self-reflect while developing skills to avoid rumination could lead to adaptive metacognition and the reduction of test anxiety (Kross \& Ayduk, 2011). The primary contribution to the scholarship community is to provide an evidence-based classroom intervention tested in a real-world school setting that is shown to help adolescents manage test anxiety (by decreasing worry and increasing self-efficacy), resulting in improved performance on a reading comprehension test. Recommendations for teachers, schools, and school divisions are discussed to provide authentic and practical elements to garner and integrate into other educational settings. These aims were addressed in the current study.

\section{Methods}

\section{Context}

Participants were students from a rural high school with a current population of 870 students (Grades 9-12) located in a town near a large Alberta city. The school population is mostly White, middle- to upper middle-class, and has a high school completion rate of $90 \%$. Seventeen percent of the students are enrolled in French Immersion, 16.8\% are coded as special needs, and 1.2\% are English Language Learners (ELL) (Cowley \& Easton, 2018). The study took place over a five-month period (September to December of 
2019) and was delivered through a psychology option course. This study was approved by the university ethics review board prior to commencing.

\section{Participants}

A total of 105 public school students (Grades 9-12; ages 14-17) participated in this study, with 35 (83\% females and 17\% males) enrolled in the psychology (intervention) class forming the Experimental group (EG). Seventy students (66\% females and 34\% males) made up the Control group (CG) and were selected from a variety of courses, including psychology and science classes. The 2019-20 academic averages of the EG and CG were $87.6 \%$ and $82.8 \%$ respectively. Students in the EG self-selected into this class with the understanding of a test anxiety reduction focus using SEL, study skills, and biofeedback techniques. The CG were students in regular programming without access to the intervention; however, these students were informed that they were a control group participating in a study examining test anxiety reduction.

\section{Procedure}

A quasi-experimental pre-test-post-test control group mixed methods design was used to determine the effects of the intervention across time and between groups. The SEL and study skills strategies along with the HF breathing technique (using the HeartMath [HM] sensor with the Inner Balance app) were integrated into a psychology option course (offered in a 50-minute class, twice per week) during the fall semester of 2019. Students were offered a letter of recruitment and from there volunteered to be in the study, forming the EG (all 35 students consented to be in the study). Students in regular classes (no added intervention) formed the CG. Recruitment and data collection were handled by the Research Assistant (RA) to minimize the dual role situation with the researcher/teacher. Data were collected at the start (September: Time 1) and end (December: Time 2) of the fall semester of 2019. The classes took place in a regular classroom with the study researcher as the lead teacher. Thirty-five HM sensors were made available to the students during each class and instruction was initially provided by a licensed HeartMath facilitator (HMF). The HM sensor connected (via Bluetooth or directly) to a student device using the Inner Balance app (HeartMath Institute, 2017b). Biofeedback from the sensor and app provided the user with information about HRV and coherence, enabling them to 
view the effects of HF breathing in real time. These data (obtained from the user devices) were not analyzed using standard statistical methods due to the large number of variables (e.g., varying time periods, achievement level preference, usage when doing other activities besides HF breathing).

The study phases are illustrated in Figure 1.

\section{Figure 1}

Flow Chart for Intervention or Regular Program Timeline

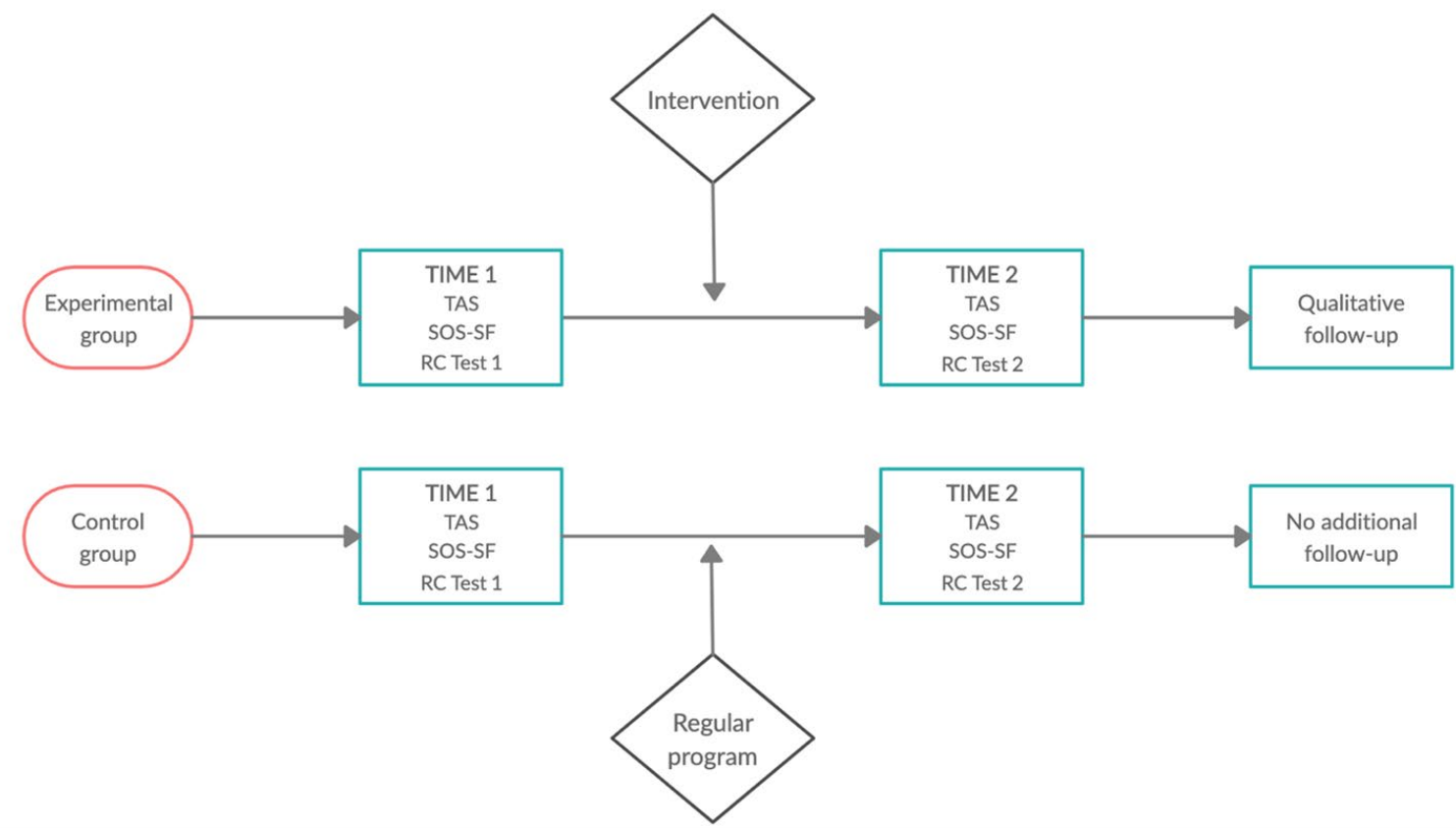

Note: A quasi-experimental design was employed due to previous student self-selection into courses, therefore unable to fully randomize participants.

TAS $=$ Test Anxiety Survey

SOS-SF $=$ Student Opinion Survey-Short Form (HeartMath Institute, 2017a)

$\mathrm{RC}$ Test $=$ Reading Comprehension Test 1 and 2

Learning outcomes in the course with intervention. Learning outcomes in the course (intervention) included the physiology of stress (focusing on brain biology and hypothalamic-pituitary axis), HM sensor application and biofeedback instruction, SEL strategies (e.g., practising gratitude, mindful breathing, communication strategies, perspective-taking, reframing, effects of emotional regulation on behaviours) and study skill strategies (elaboration, chunking, mnemonics, time management, text annotation, and 
concept mapping). All eight modules of the HeartMath Institute's SBWH program were integrated into the classroom instruction (Smart Brain Wise Heart, 2020). After each HF breathing session, students would self-report their HRV biofeedback metrics from their Inner Balance app on their device. Students were able to observe coherence and achievement measurements, collect badges, and advance levels through the Inner Balance app. Participation in the study did not affect the overall grade, as study measurements and grade assessments were separate, in keeping with requirements from the ethics review board.

\section{Quantitative Measures}

Two student surveys were used to measure test anxiety and emotional well-being at Times 1 and 2. The Test Anxiety Survey (TAS) was an online inventory adapted (to identify the domains most affected by test anxiety) from a previously modified Spielberger (1980) test anxiety survey (Driedger, 2019). The original Spielberger TAI was designed as a self-report test to measure situation-specific individual differences in test anxiety and organized the data around three central subscales: test-anxiety worry, test-anxiety emotionality, and test-anxiety total (Ayalp \& Özdemir, 2016). The reliability values (using alpha coefficients for subscales) were TAI-T: 0.96; TAI-W: 0.91; and TAI-E: 0.91 (Spielberger, 1980, as cited in Ayalp \& Özdemir, 2016). The TAS used in this study was an expanded version of the Spielberger TAI consisting of 50 items using a 4-point Likert scale (1-almost never, 2-sometimes, 3-often, 4-almost always) with six items reversescored. An example from the TAS is Item 18: "When I think about my future depending in part on doing well on exams, it upsets me." A generalized least-squares factor analysis with a Varimax rotated factor solution was conducted on the TAS Time 1 data. An inspection of Eigen Values supported a 5-factor solution. Items with factor loading values higher than .4 or lower than -.4 were included, resulting in five interpretable factors consisting of seven to 11 items each. The five factors that were identified were physiological effects of test anxiety, self-efficacy for test-taking, worry about future social stress, negative perceptions of tests, and worry of social standing. Participant factor scores were used in subsequent analyses. The Student Opinion Survey-Short Form (SOS-SF), developed by the HeartMath Institute, assessed students on four factors: positive affect, negative affect, stress behaviours, and stress management (HeartMath Institute, 2017a). The 
SOS-SF is comprised of 26 items, using a 4-point Likert scale identical to the TAS. An exploratory principal components factor analysis resulted in four distinct factors (positive affect, negative affect, stress behaviours, and stress management) with four to seven items loading on each factor.

Two different (but similar difficulty level) reading comprehension (RC) tests (Test Prep Review, 2020) were used to simulate a test-taking situation to measure relative academic performance at Times 1 and 2. TAS, SOS-SF, and reading comprehension scores at Times 1 and 2 were analyzed using a repeated measures analysis of variance (RM-ANOVA) within the SPSS statistical analysis program. A covariate was not applied, as the two groups had mean RC test scores differing by only $8.9 \%$ at Time 1 . Missing data involved a small number of respondents (five) who had a low number of blank item responses (one to three) in their data sets. In all cases, missing responses were replaced with the respondent's average item response.

\section{Qualitative Measures}

Brief individual semi-structured interviews were conducted by the RA and HMF to collect student subjective experiences and personal reflections. Ten questions were pre-selected and student responses were audio-recorded and transcribed, with responses grouped in six themes according to the percentage of students who discussed that topic during their interview. Occasionally, follow-up questions were asked for clarification when student responses were not clear. For example, after a student response, the interviewer said, "Tell me a bit about that - when you say 'catch yourself,' what do you mean by that?" Examples of student statements are provided in Table 4. The shortest interview was five minutes, 10 seconds, while the longest was 18 minutes, 45 seconds (average interview time was 10 minutes, 20 seconds). Thirty-one students were interviewed in person in February 2020, while four students were interviewed in March 2020 via Zoom, due to COVID-19 restrictions. Consent forms were collected as per the university ethics review board requirements and participants were assigned pseudonyms. A focus group session at program completion provided further insight into collective student perceptions. Focus groups can often generate richer conversations and extend ideas in a collaborative way such that the researchers can further understand how participants think and feel about their collective experience (Gill et al., 2008). Group comments were 
recorded on large posters and analyzed for common themes according to the frequency of responses. Sample group comments are included in Table 5.

\section{Results}

\section{Quantitative Results}

Test Anxiety Survey (TAS). Correlations among the TAS factor scales at Times 1 and 2 were all moderate, between .56 and .79. To check for overall significance, a 2 Groups (E/C) by 2 Times Repeated Measure MANOVA (O’Brien \& Kaiser, 1985) was conducted with all five TAS scales included. The results showed a significant Group by Time Interaction effect $(\mathrm{F}(1,85)=3.03, \mathrm{P}<.01)$ and as such RM-AVOVAs were run for each TAS scale to examine possible main and interaction effects for each scale. Scale scores were calculated for each participant by summing their ratings (reverse scored where required) of each item loading on each factor to produce five scale scores (scales) for each participant. These scales were then subjected to RM-ANOVAs to determine the difference in mean scores between groups and within groups (from Time 1 to Time 2) on each scale, and to examine the interaction effect between group and time (Table 1).

The Test-Taking Self-Efficacy and Preparation scale returned a significant interaction effect, $F(1,85)=5.850, p=.018$ (see Figure 2 ), and medium effect size (.50), meaning there was a moderate magnitude of difference in the mean scores between the groups across two time periods (Sullivan \& Feinn, 2012) (see Table 1). Self-efficacy increased by $5.3 \%$ in the EG, however decreased by $8.4 \%$ in the CG. Simple main effects (via a univariate ANOVA comparing the groups at Times 1 and 2) indicate a significant difference, $(F(1,116)=5.980, p<.05$, in mean scores between the two groups at Time 1 , but not at Time 2. Additionally, simple main effects for RM-ANOVAs were run separately for each group across Times 1 and 2 indicating a significant difference $F(1,62)=8.432$, $p=.005)$ for the CG but not for the EG. The measure of test-taking self-efficacy for the EG from Time $1(M=16.54, S D=1.10)$ to Time $2(M=17.42, S D=1.02)$ shows a slight but non-significant increase. Even with the additional stress of upcoming tests and exams at the end of the semester (Time 2), their ability to handle the test-taking situation 
(self-efficacy) was relatively stable. However, the CG measured a significant decrease in self-efficacy from Time $1(M=19.57, S D=.68)$ to Time $2(M=17.92, S D=.63)$, suggesting they may have been unsure as to how to handle upcoming tests and exams at Time 2.

\section{Figure 2}

Hypothetical Trend for the Experimental Group Without the SEL/HM Program

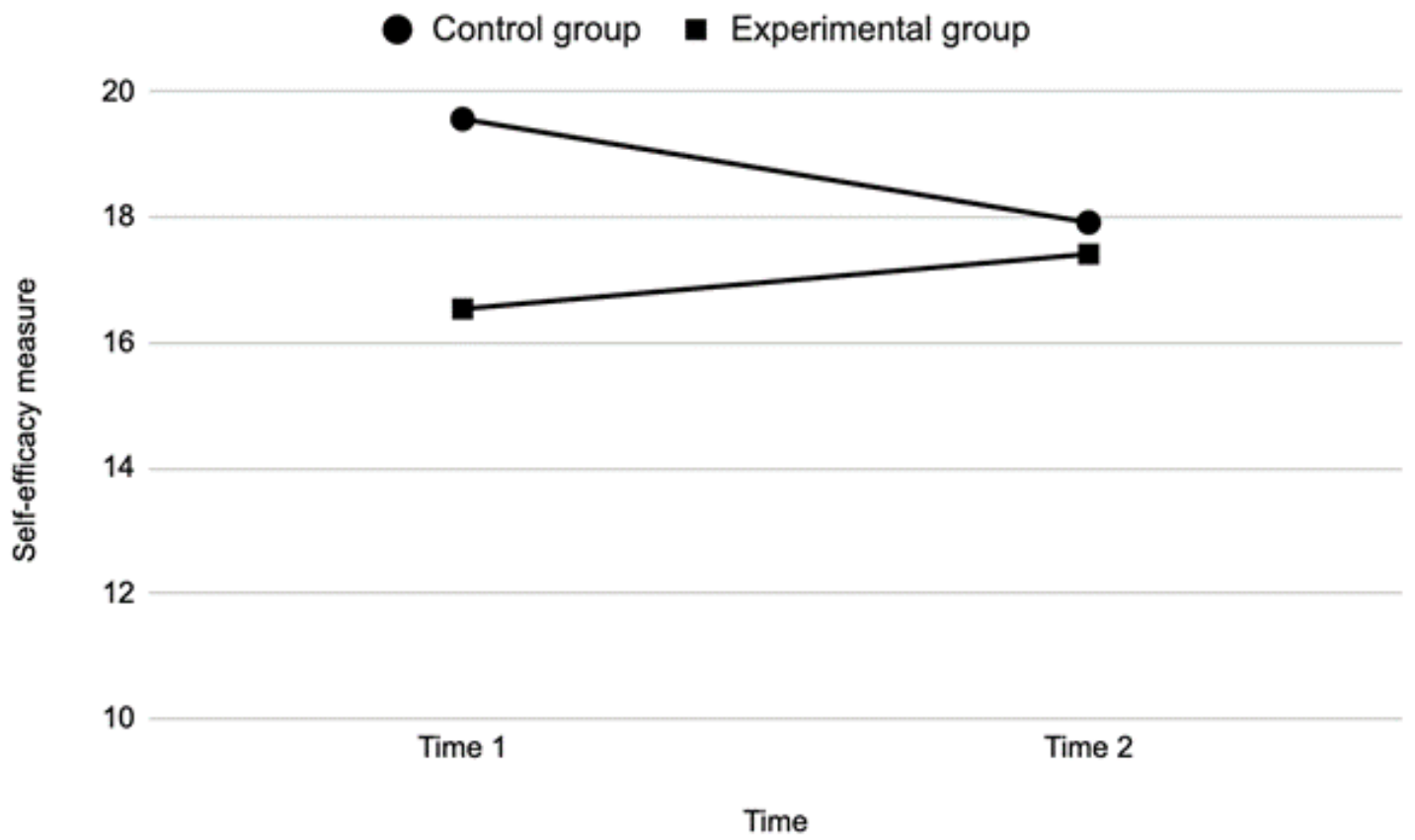

The scale measuring Worry about Future Social Stress included concern for the future, social desirability, and worry about reaching desired goals. An RM-ANOVA confirmed a significant interaction effect $F(1,85)=9.135, p=.003)$ with a medium effect size (.65). The two main effects reveal a non-significant group effect $F(1,85)=0.065$, $p=.799$ and a marginally significant time effect $(F(1,85)=3.257, p=.075$. At Time 1 (see Figure 3$)$, the EG $(M=23.46, S D=5.62)$ measured higher levels of worry of future social stress compared to the CG $(M=19.73, S D=5.55)$. At Time 2 , the EG $(M=21.92$, $S D=4.24)$ is more in line with the $\mathrm{CG}(M=21.03, S D=6.26)$. Additionally, simple main effects were run separately for each group across Times 1 and 2 indicating a significant difference for both the $\mathrm{CG} F(1,62)=6.166, p=.016$ and the $\mathrm{EG} F(1,23)=5.608$, 
$p=.027$. The presence of tests and pressure of upcoming exams at Time 2 were notable events that may have played a role in this increase in worry, however the EG decreased their stress and worry, likely due to the acquisition of new coping strategies.

\section{Figure 3}

Mean Scores for Worry of Future Social Stress

Control group Experimental group

25

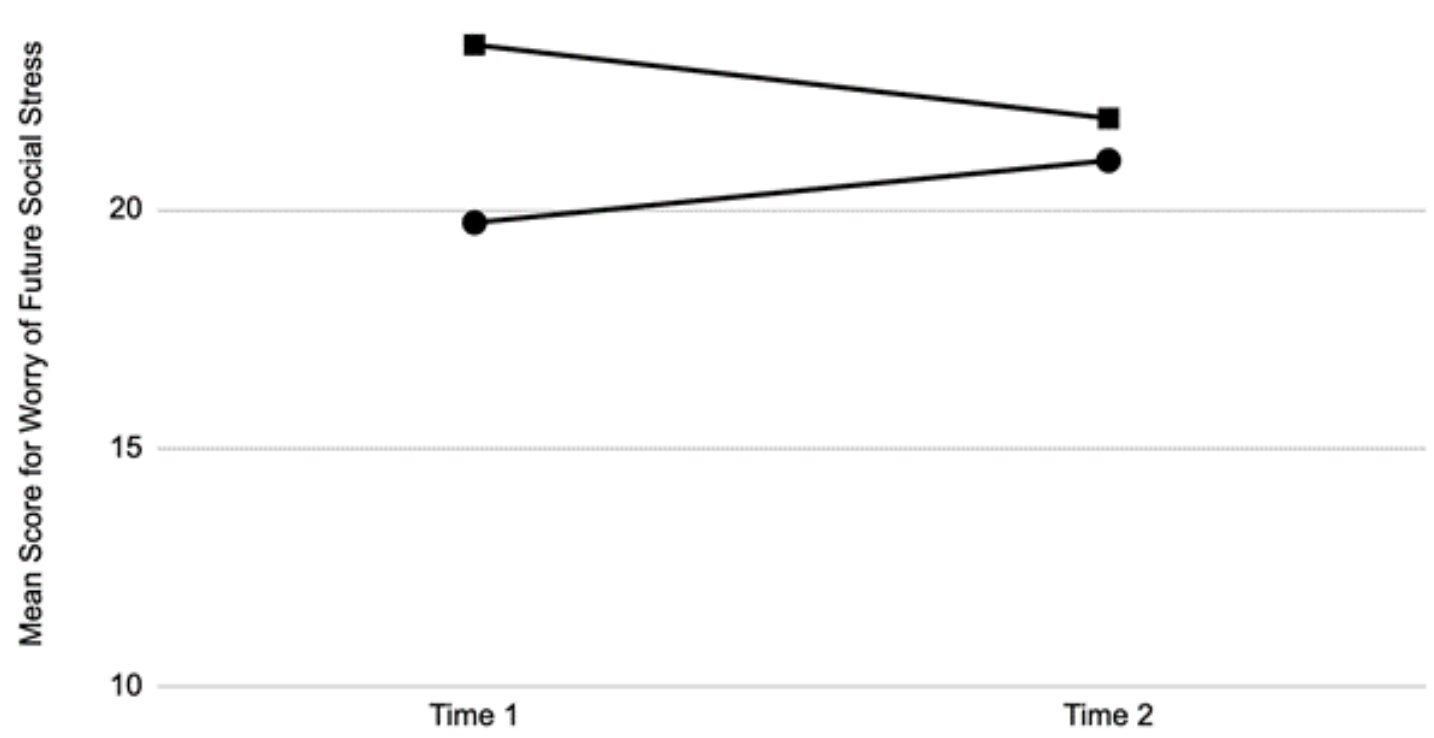

Note. This graph shows the change in worry of future social stress indicating upcoming tests, effect of test marks on future, and social standing. High scores correlate to higher worry levels.

The scale measuring Negative Perception of Tests revealed no significant difference between groups or within groups for this measure. Items from the TAS indicated feelings of dread around the prospect of having tests and exams. At Time 1, the Experimental group $(M=21.63, S D=5.06)$ was slightly higher compared to the Control group $(M=20.02, S D=5.26)$, and at Time 2, the Experimental group $(M=22.38, S D=4.81)$ was still slightly higher than the Control group $(M=20.62, S D=5.21)$.

The scale measuring Social Standing Worry centred on students' perceptions of themselves in relation to others, such as their peers, teachers, and parents. Many students indicated heightened stress around others knowing their marks, parent pressure, and 
disappointing teachers, ultimately affecting their perception of social standing. At Time 1 , the EG $(M=25.82, S D=6.39)$ measured higher scores as compared to the $\mathrm{CG}(M=$ $22.21, S D=6.31)$. At Time 2 , the EG $(M=24.79, S D=5.52)$ was still higher than the $\mathrm{CG}$ $(M=23.03, S D=5.91)$, however the EG showed a decrease in worry of social standing, whereas the CG showed a slight increase. While the initial group effect was significant $F(1,83)=4.4, p=.039$, the downward trend for the EG was not significant; however, this group was possibly just learning how to reduce their worries about social standing and external judgement.

\section{Table 1}

RM-ANOVA of Experimental and Control Groups for Times $1 v 2$ for the Factors from the Test Anxiety Survey (TAS)

\begin{tabular}{|c|c|c|c|c|c|c|c|}
\hline & \multicolumn{2}{|c|}{ Experimental group $(N=24)$} & \multicolumn{2}{|c|}{ Control group $(N=63)$} & \multirow[t]{3}{*}{$F$} & \multirow[t]{3}{*}{$p<$} & \multirow[t]{3}{*}{$E S$} \\
\hline & Time 1 & Time 2 & Time 1 & Time 2 & & & \\
\hline Factor & $M(S D)$ & $M(S D)$ & $M(S D)$ & $M(S D)$ & & & \\
\hline $\begin{array}{l}\text { Physiological ef- } \\
\text { fects of test anxiety }\end{array}$ & $29.90(8.86)$ & $28.75(8.83)$ & $25.54(8.41)$ & $26.95(8.52)$ & 1.81 & ns & .29 \\
\hline $\begin{array}{l}\text { Self-efficacy for } \\
\text { test-taking }\end{array}$ & $16.54(1.10)$ & $17.42(1.02)$ & $19.57(.68)$ & $17.92(.63)$ & 5.85 & .05 & .50 \\
\hline $\begin{array}{l}\text { Worry about future } \\
\text { social stress }\end{array}$ & $23.46(5.62)$ & $21.92(4.24)$ & $19.73(5.55)$ & $21.03(6.26)$ & 9.135 & .01 & .65 \\
\hline $\begin{array}{l}\text { Negative percep- } \\
\text { tions of tests }\end{array}$ & $21.63(5.06)$ & $22.38(4.81)$ & $20.02(5.26)$ & $20.62(5.21)$ & .023 & ns & .03 \\
\hline $\begin{array}{l}\text { Worry of social } \\
\text { standing }\end{array}$ & $25.82(6.39)$ & $24.79(5.52)$ & $22.21(6.31)$ & $23.03(5.91)$ & 1.520 & ns & .26 \\
\hline
\end{tabular}

*Effect Size (ES) using Wilson (2020).

SOS-SF Results. Correlations among the SOS scales at Times 1 and 2 were all moderate, between +/- .25 and .67. To check for overall significance, a 2 Groups (E/C) by 2 Times Repeated Measure MANOVA (O’Brien \& Kaiser, 1985) was conducted with all four SOS scales included. The results showed a significant main effect for Group $(F(1$, $83)=2.46, p<.05)$ and as such RM-AVOVAs were run for each SOS scale to examine possible main and interaction effects for each scale.

The Positive Affect scale assesses general happiness and optimism at the time the survey was taken. Statements such as "I feel happy," "I feel appreciative," "I feel calm," 
"I feel enthusiastic," "I feel hopeful," and "I feel loved" were the items measured. Students in the EG $(\mathrm{N}=28)$ showed an increase in positive affect from Time $1(M=17.18$, $S D=3.03)$ to Time $2(M=18.07, S D=2.89)$, while the CG $(N=60)$ showed a slight decrease in positive affect from Time $1(M=18.67, S D=3.02)$ to Time $2(M=18.28, S D$ $=3.43)$. There was a significant interaction effect and small effect size (.45) for positive affect between groups and across time $F(1,83)=4.450, p=.038$. The EG experienced a higher positive affect at the end of the course, whereas the $\mathrm{CG}$ decreased slightly.

The Negative Affect scale assesses general negative feelings. Statements such as "I feel stressed," "I feel lonely," "I feel sad," "I feel angry," and "I feel disappointed" were the items that loaded for this factor. The EG $(M=14.32, S D=3.62)$ started out higher in negativity than the CG $(M=12.63, S D=3.41)$; however, the EG $(M=13.64$, $S D=3.13)$ lowered their negative affect, whereas the CG $(M=13.53, S D=3.55)$ increased in negative affect. There was a significant interaction effect and medium effect size (.50) for feelings of negative affect between groups and across time $F(1,83)=5.415$, $p=.022$, meaning the EG decreased negative affect at Time 2 and in comparison to the CG. Simple main effects analysis indicates significantly higher negative affect in the EG at Time 1 compared with the CG, however from Time 1 to Time 2 the EG displayed no significant effect, meaning they generally maintained their affect despite having increased stressors such as tests, exams, and major assignments to deal with. In comparison, the CG increased in negative affect at Time 2 , although not significantly.

The Stress Behaviours scale identifies student responses to stressful situations, with items such as "I try to manage my stress the moment it happens," "I try to breathe deeply or relax to calm myself down," and "I find it helpful to do physical exercise or some other activity." While the results were not significant, the EG decreased their stress behaviours, whereas the CG remained similar from Time 1 to 2 .

The Methods of Handling Stressful Situations scale includes items such as "I am able to calm down when feeling stressed," "I try to be less judgemental when feeling angry at myself," and "I try to feel more peaceful when I'm feeling anxious." These items organized themselves around a change in attitude during stress and the ability to handle the stressful situations. The Time 1 and 2 results were not significant. 


\section{Table 2}

RM-ANOVA of Experimental and Control Groups for Times $1 v 2$ for the Factors from SOS-SF Survey

\begin{tabular}{|c|c|c|c|c|c|c|c|}
\hline & \multicolumn{2}{|c|}{ Experimental group $(N=28)$} & \multicolumn{2}{|c|}{ Control group $(N=60)$} & \multirow[t]{2}{*}{$F$} & \multirow[t]{2}{*}{$\overline{p<}$} & \multirow[t]{2}{*}{$E S$} \\
\hline & Time 1 & Time 2 & Time 1 & Time 2 & & & \\
\hline Factor & $M(S D)$ & $M(S D)$ & $M(S D)$ & $M(S D)$ & & & \\
\hline Positive affect & $17.18(3.03)$ & $18.07(2.89)$ & $18.67(3.02)$ & $18.28(3.43)$ & 4.450 & .05 & .45 \\
\hline Negative affect & $14.32(3.62)$ & $13.64(3.13)$ & $12.63(3.41)$ & $13.53(3.55)$ & 5.415 & .05 & .50 \\
\hline Stress behaviours & $9.14(2.69)$ & $9.89(1.97)$ & $8.60(2.21)$ & $9.03(2.02)$ & .359 & $\mathrm{~ns}$ & .13 \\
\hline $\begin{array}{l}\text { Handling stress } \\
\text { by attitude }\end{array}$ & $13.86(3.57)$ & $14.00(3.36)$ & $14.17(3.51)$ & $14.38(3.78)$ & .007 & ns & NA \\
\hline
\end{tabular}

*Effect Size (ES) using Wilson (2020).

Reading Comprehension Test results. Students in both groups were given a Reading Comprehension (RC) test at Time 1 and Time 2. An RM-ANOVA run for RC test scores between groups from Time 1 to 2 showed a significant interaction, $F(1,103)=$ $10.7, p=.001$ (see Figure 4) and medium effect size (.64) (Table 3). Simple main effects analysis indicated that the $\mathrm{T} 1$ and $\mathrm{T} 2 \mathrm{RC}$ score differences were significant for the $\mathrm{CG}$ $(6.69$ to $9.40, F(1,69)=52.4, p<.001$ and the $\mathrm{EG}(7.31$ to $12.14, F(1,34)=84.3, p<.001$. The EG RC mean scores did not differ from those of the CG at Time 1 (7.31 vs. 6.69) but were significantly higher than the $\mathrm{CG}$ at Time $2(12.14$ vs 9.40$), F(1,104)=22.4, p<.001$. The EG improved their test score by $32 \%$ while the CG improved theirs by $18 \%$.

\section{Table 3}

Repeated Measures ANOVA of Experimental and Control Groups for Times $1 v 2$ for the Reading Comprehension Tests

\begin{tabular}{|c|c|c|c|c|c|c|c|}
\hline & \multicolumn{2}{|c|}{ Experimental group $(N=35)$} & \multicolumn{2}{|c|}{ Control group $(N=70)$} & \multirow[t]{3}{*}{$F$} & \multirow[t]{3}{*}{$p<$} & \multirow[t]{3}{*}{$E S$} \\
\hline & Time 1 & Time 2 & Time 1 & Time 2 & & & \\
\hline Factor & $M(S D)$ & $M(S D)$ & $M(S D)$ & $M(S D)$ & & & \\
\hline $\begin{array}{l}\text { Reading } \\
\text { Comprehension } \\
\text { test scores }\end{array}$ & $7.31(3.04)$ & $12.14(2.10)$ & $6.69(2.32)$ & $9.40(3.17)$ & 10.67 & .01 & .64 \\
\hline
\end{tabular}




\section{Figure 4}

Mean Scores on Reading Comprehension Tests

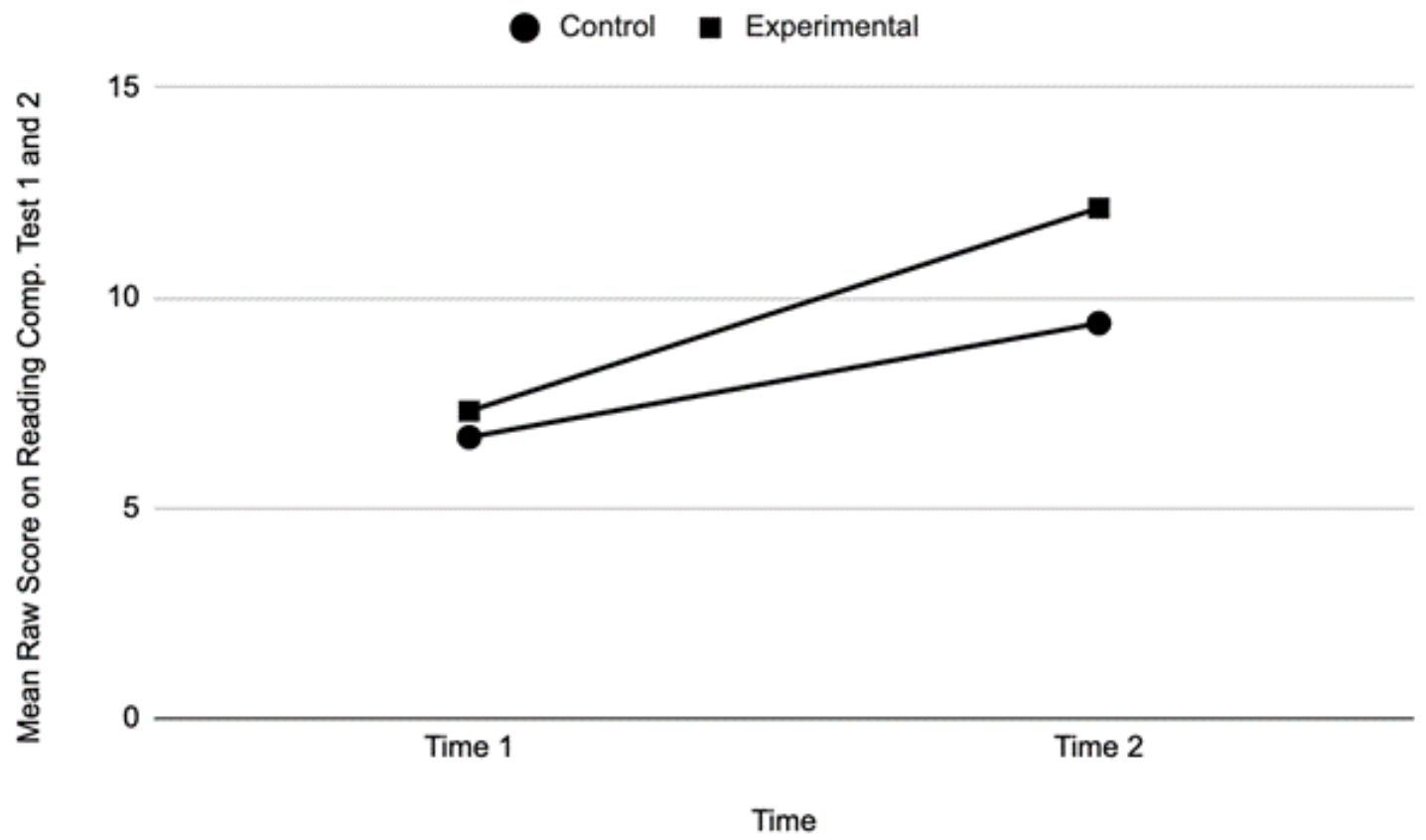

Note: Mean scores on Reading Comprehension Tests taken over two time periods. Each time period had a different multiple-choice reading comprehension test scored out of a total of 15 marks. Students had not seen either test previously and both were constructed at a Grade 9 difficulty level.

Inner Balance app data. Data retrieved from student devices indicated (anecdotally) that at Time 1, 78\% of the students selected Level 1 while 22\% selected Level 2. At Time 2, 21\% of students selected Level 1,67\% selected Level 2, with the remaining $12 \%$ using Level 3. Each level is $15 \%$ more difficult to achieve the same coherence score on the app (HeartMath Institute, 2017b), thus moving up a level but maintaining similar coherence scores (as was the case from the student data) indicates some mastery of the HF breathing technique. 


\section{Qualitative Results}

\section{Student Interview Theme Analysis}

Themes centred on test experience perceptions and resulting impairments from previous anxiety levels, descriptions of skills and strategies acquisition from participation in the course, and a clear understanding of the effects of HF breathing on lowering stress levels. A tally of the number of students whose statements aligned with each theme is displayed in Table 4. Every student responded with an almost identical description of the test anxiety experience, suggesting that these effects and perceptions are fairly universal in students with self-identified test anxiety. Students described their bodily reactions to test-taking as physical, citing sweaty palms, shakiness, headaches, stomach aches, racing heartbeat, shallow breaths, and crying. They described these physiological effects of test anxiety as having a deleterious effect on their test performance, resulting in lower grades. Many students also commented on an inability to focus and concentrate, their mind going blank, and difficulty reading and answering the questions. Some altered their test-taking perception slightly, while others indicated a continued dislike of tests. The TAS confirmed a slight but non-significant increase in test perception positivity, meaning many students continued to dread the test situation, even after the acquisition of SEL and mindfulness skills. Students commented on worry over future social stress, including classmates finishing the test earlier, tests affecting subsequent academic pathways, and parent pressure and possible reprimand if the results were not as expected. The TAS revealed a significant decrease in worry about future social stress at Time 2 , indicating less worry about the test score outcomes and social judgements as a result.

Students enjoyed discussing their ability to access breathing techniques and calming methods for test-taking situations. Many commented on using the sensors, or simply taking a few minutes before the test to centre, focus, and breathe. Students described using the breath to decrease anxiety and increase coherence visualized through the biofeedback of staying in the green zone. Students indicated feeling more control over their emotions with new tools to draw upon when faced with stressful situations such as tests, or even difficult conversations, describing an overall increase in self-efficacy, corroborating the quantitative data findings. Table 4 depicts common themes derived from student 
interview transcripts, indicating the percentage of students offering statements supporting that theme.

\section{Table 4}

\section{Qualitative Theme Analysis from Student Interviews}

\begin{tabular}{|c|c|c|}
\hline Theme & $\begin{array}{l}\text { Percentage } \\
\text { of students } \\
\text { whose } \\
\text { interview } \\
\text { contains } \\
\text { theme }\end{array}$ & Student(s) quote example(s) \\
\hline $\begin{array}{l}\text { Students perceive } \\
\text { tests to be stressful, } \\
\text { anxiety-provoking }\end{array}$ & $100 \%$ & $\begin{array}{l}\text { "I just start panicking, like rushing, like going over it too fast and... } \\
\text { it's kind of like a rush of cold sweat and then it's like I'm panicked, } \\
\text { little shaky [and] all of my thinking just kind of gets all mixed up } \\
\text { and jumbled all together and I could be like reading a question and I } \\
\text { have to keep reading it over and over again." (Doris) }\end{array}$ \\
\hline $\begin{array}{l}\text { Test anxiety lowers } \\
\text { their performance } \\
\text { on tests. }\end{array}$ & $100 \%$ & $\begin{array}{l}\text { "On assignments and small quizzes, I do super great, like high 90s } \\
\text { or whatever, but on tests I get super anxious and I just don't know } \\
\text { anything so I always get really crappy marks and I think that reflects } \\
\text { on me, like I'm a bad student." (Beatrice) }\end{array}$ \\
\hline $\begin{array}{l}\text { Students worry } \\
\text { about future social } \\
\text { stress. }\end{array}$ & $46 \%$ & $\begin{array}{l}\text { "I guess it's just feeling really, really worried about how your test } \\
\text { is going to go, the mark you're going to get, how you're going to } \\
\text { do, in reference to other people who are also in the class with you." } \\
\text { (Ralph) }\end{array}$ \\
\hline $\begin{array}{l}\text { Students now have } \\
\text { strategies to man- } \\
\text { age test anxiety and } \\
\text { improve perfor- } \\
\text { mance. }\end{array}$ & $100 \%$ & $\begin{array}{l}\text { "I've learned how to get myself in a state of high coherence and } \\
\text { a way to calm myself down when experiencing such anxiety with } \\
\text { regards to tests and it enables me to, you know, be able to think } \\
\text { clearer." (Bill) }\end{array}$ \\
\hline $\begin{array}{l}\text { Students have im- } \\
\text { proved self-aware- } \\
\text { ness and self-effi- } \\
\text { cacy. }\end{array}$ & $89 \%$ & $\begin{array}{l}\text { "When I'm drawing a blank, it's helped me realize that it's more } \\
\text { within my power to change how I take tests and it's not all purely } \\
\text { about the subject matter of the test, I can also relate to how I'm } \\
\text { taking the test." (Nancy) }\end{array}$ \\
\hline $\begin{array}{l}\text { Students experi- } \\
\text { enced a change in } \\
\text { test perception. }\end{array}$ & $63 \%$ & $\begin{array}{l}\text { "It just helps to like take a minute and just focus on your breathing } \\
\text { and make sure your mind is clear so don't try to think of anything, } \\
\text { like negative thoughts just positively thinking that you're going to } \\
\text { do well on the test". (Joyce) }\end{array}$ \\
\hline
\end{tabular}

Note. Students were interviewed individually and audio-recorded by one of the RAs post intervention. 


\section{Focus Group Theme Analysis}

Students discussed their thoughts, feelings, and impressions of the course components in small focus groups. Many of the themes that emerged mirrored those from the interviews (see Table 5), such as believing that test anxiety negatively affected performance but that strategies like HF breathing and study skills enabled them to handle tests with greater confidence and success. The collaborative efforts of the students revealed an overwhelmingly positive analysis of the course and benefits to them. However, one must be cognizant of the potential for group think, particularly with adolescents. A disadvantage of the focus group format is that an individual might not want to voice their opinion if it went against others in the group, instead concurring with the group statements (Jayanthi \& Nelson, 2002).

\section{Table 5}

Qualitative Theme Analysis from Student Focus Groups

\begin{tabular}{|c|c|c|}
\hline Theme & $\begin{array}{l}\text { Number of } \\
\text { group state- } \\
\text { ments describ- } \\
\text { ing this theme }\end{array}$ & Group quote example(s) \\
\hline $\begin{array}{l}\text { Heart-focused } \\
\text { breathing with bio- } \\
\text { feedback decreases } \\
\text { stress. }\end{array}$ & 32 & $\begin{array}{l}\text { "I really enjoyed this class. I try to use my heart-focused breath- } \\
\text { ing whenever I am overwhelmed, can't sleep, or am really } \\
\text { anxious." (Group 7) }\end{array}$ \\
\hline $\begin{array}{l}\text { Improved test-taking } \\
\text { outlook. }\end{array}$ & 22 & $\begin{array}{l}\text { "I've learned that it is all the way you look at [tests] and prepare. } \\
\text { Also, if you have the correct techniques you will find that they } \\
\text { become easier. I find them much less stressful and they don't } \\
\text { scare me now." (Group 3) }\end{array}$ \\
\hline $\begin{array}{l}\text { Acquisition of new } \\
\text { study/test-taking } \\
\text { skills. }\end{array}$ & 13 & $\begin{array}{l}\text { "I learned how to better understand myself and have new tech- } \\
\text { niques that I can use to re-ground/centre myself. I also have new } \\
\text { memory techniques that I have used on tests, and my test grades } \\
\text { have actually gone up now that I use them." (Group 3) }\end{array}$ \\
\hline $\begin{array}{l}\text { Learned about heart- } \\
\text { brain coherence. }\end{array}$ & 12 & $\begin{array}{l}\text { "I learned that stress triggers a fast heart rate and that breathing } \\
\text { can slow the stress down." (Group 8) }\end{array}$ \\
\hline $\begin{array}{l}\text { Course was useful/ } \\
\text { would recommend. }\end{array}$ & 21 & $\begin{array}{l}\text { "We think this course has been beneficial and has helped us man- } \\
\text { age our stress." (Group 7) }\end{array}$ \\
\hline
\end{tabular}

Note. Students were organized into eight self-selected groups, with two to five members in each group. Students discussed pre-set questions and wrote answers on poster paper. 


\section{Discussion}

This study revealed that a classroom-based intervention combining SEL and study skill strategies along with HF breathing techniques using biofeedback helped reduce feelings of test anxiety and worry, increased self-efficacy, and improved academic performance.

\section{Student Perceptions of Test Anxiety}

The students, through surveys, interviews, and focus group discussions, identified a number of direct negative cognitive, emotional, and behavioural effects related to test anxiety. Due to self-selection into this program, students in the EG started the course with relatively higher physiological arousal levels, higher levels of worry about the future and social stress, higher negative affect (and lower positive affect), and a more negative perception of tests than the CG. Interestingly, the students did not change their view of the test-taking experience significantly, indicating a continued dislike for them, contrary to individuals with low test anxiety who view tests as a challenge and approach them with enthusiasm (Zeidner, 1998). It was also likely (and observed anecdotally) that these negative perceptions and heightened emotionality around tests had been part of their lives for a substantial amount of time (likely throughout their school career), thus continually negatively reinforcing thoughts and feelings of test writing and preparation.

\section{Reduced feelings of worry and negative outlook as a result of the SEL/HM pro-}

gram. The students in the EG significantly decreased their worry about social situations (perceived judgement from peers, parents, or teachers) and defeatist thinking compared to the CG. Students commented that learning about managing stress through HF breathing and reframing techniques helped put things into perspective, enabling them to worry less about things beyond their control. The procurement of these new ways of thinking and feeling, along with additional positive social and behavioural skills in a relatively short period of time speaks to the ability for adolescents to build resiliency, when housed within a safe and caring environment and the delivery of effective SEL strategies. Previous research into brain plasticity and cognitive development has demonstrated that adolescence is an optimal time for neural pruning and rewiring and that implementing SEL and resilience interventions coincides with teenagers' adaptable neural circuits (Bradshaw et 
al., 2012), helping to improve emotional control while decreasing negative internalizing behaviours such as brooding and rumination (Seiden, 2020).

Increased self-efficacy for emotional regulation and test-taking. Students in the EG had the opportunity to learn HF breathing and calming techniques through teacher and HM facilitator modelling followed by practice with the biofeedback sensors to observe the effect on themselves. Students were rewarded through app badges, level upgrades, and teacher recognition for their efforts, fostering their belief that they possessed the skills to self-regulate. Evidence that students can strengthen self-efficacy and self-esteem is gaining momentum in growth mindset and resiliency-building research currently being investigated in educational settings (Polirstok, 2017). Yeager and colleagues (2016) found that adolescents transitioning to high school achieve greater motivation when they believe they can handle their school-related tasks, feel psychologically safe and valued, and their efforts and accomplishments will be rewarded. Acquiring SEL skills appears to have a bidirectional effect, as lowering stress and worry reactions leads to increased self-efficacy, leading to further reduced stress and worry as the individual gains control and reassurance of having the capabilities required to handle the stressful situation. The students in the EG increased self-efficacy and decreased worry of social stress and negative affect. It is entirely likely that these outcomes became interwoven, both in their development and result, benefitting the students in a "double whammy" type of effect. This application of mindfulness embedded into a SEL based program, allowed students to first calm down and then be regulated cognitively and emotionally for the acquisition and practice of new strategies. The moderate effect size obtained in this study validates the overall impact on student understanding and awareness of their ability to self-regulate and effectively handle themselves in test-taking situations.

\section{Improved academic performance after completion of the SEL/HM program.}

Both groups improved their RC test performance, possibly a result of learning and development throughout the semester, or due to a slightly easier or more engaging second test; however, the EG were significantly more successful. Students indicated that learning test-taking strategies helped them organize their notes, annotate text, and analyze answers. Their new ability to use HF breathing to calm erratic and distracted thinking helped them focus and think clearly throughout the test, improving their reading, 
analyzing, and problem-solving capabilities. When students are calm and believe they possess the tools to engage with the material, they are able to focus more clearly and access the higher order thinking skills needed for memory retrieval and complex problem analyses.

\section{Gaps in the Curriculum for SEL Programming}

Weems and colleagues (2014) found that SEL learning decreased overall test anxiety and externalized emotionality such that it should be integrated into regular school curricula as a preventive measure, to assist students with their social-emotional regulation before they suffer the negative effects of elevated stress. Helping students develop resiliency, potentially preventing some of the adverse downstream emotional dysregulation is of great benefit to students' overall well-being and school performance. Providing evidence-based, thoroughly vetted SEL programs that are accessible to busy classroom teachers is essential to the integration of these preventative learning strategies. Durlak and colleagues (2011) indicated that SEL programs have been studied least often in high schools and rural settings, both applicable to this study. In addition to this research gap, only $16 \%$ of the studies that were reviewed provided information about academic achievement, and only $32 \%$ assessed social and emotional skills as an outcome (Durlak et al., 2011).

At present, there are few standardized assessment tools for SEL competencies, once called "soft skills," that might now be considered "essential skills" as they become increasingly necessary for effective social interaction and communication in the larger global community. Additionally, studies looking at the effects of SEL programs on smaller marginalized groups are sparse and unclear as to whether some groups would benefit more or less than others (Durlak et al., 2011). Clearly a barrier to universal SEL implementation into school curricula is funding, as professional development for teachers and school staff is often required (Oberle et al., 2016). Other barriers might include the expensive HM sensors; however, with wearable technology currently exploding onto the market, future students will likely have their own technology with a variety of personal physiological metrics. 


\section{Recommendations for Schools and Teachers}

Not only is teacher buy-in required to implement effective SEL programs, but a schoolwide shared vision and common approach toward how SEL initiatives fit into the school ecology is imperative (Lawlor, 2014). More research into implementation and evaluation of SEL programming will be required in order to ensure proper program dissemination and high treatment fidelity (Domitrovich et al., 2017). Additional research into the effectiveness of carry-over effects beyond the classroom (Durlak et al., 2011), specific SEL components, and effects on diverse learners is needed to determine dosage and developmental appropriateness for each program. This study employed a multi-pronged approach including SEL and study skills to target test anxiety. While this approach has many positive attributes, such as teaching students to use their breath to calm down, while teaching other social skills and test-taking strategies, it was difficult to ascertain which components produced the positive effects observed. Further delineation of the program components aligned with specific assessments could be used to determine the program elements most efficacious for each skill or learning acquisition. Following that, the integration of these elements into an elective program such as a psychology course may provide an opportunity for students to acquire these skills.

\section{Limitations and Future Directions}

There were several limitations to this study. The RC tests were not counted as regular marks, and were instead used only for the purposes of collecting quantitative data, and thus likely did not produce the same level of test anxiety and stress otherwise present in curricular grade-determining tests. Another limitation was the positive effect of the teacher relationship as a possible, and to date unmeasured, effect on the learning and measured outcomes. The EG developed a strong rapport with the teacher (this researcher) from the outset, leading to a high degree of trust and engagement. While some of the CG students were taught by this researcher, approximately half were taught by a different teacher, who had a different relationship with their students, possibly affecting the amount of student buy-in and motivation. It is also worth noting that two students described HF breathing as boring at times, mentioning that five minutes was too long to just breathe. One of the challenges with mindfulness interventions such as meditative breathing for 
children and adolescents is that some will become bored and lose interest in the activity (Keller et al., 2017). The gamification of apps such as Inner Balance helps to keep students engaged, with the ability to achieve badges and "level up" for increased challenges, appealing to youth and children with shorter attention spans.

Finally, there was a lack of ethnic diversity amongst both groups, and therefore more difficulty generalizing the data to other student populations in more multicultural school settings. As well, the students were mainly rural, with many residing on large acreages with few neighbours, distinctly different than many urban, high-density dwellers. Worldviews and individual perceptions could vary between this study group and the larger global population of students; thus additional research targeting various population subgroups may be warranted. The program itself was only offered in English and was not scaffolded for other diverse learners, who might require additional supports according to individualized program plans and predetermined accommodations.

Future directions involve further development of elective courses for high school students offering SEL and study skills to help students lower stress, increase self-efficacy, and achieve greater success in test-taking situations. Additionally, SEL skills rubrics require more investigation and empirical research to determine which aspects need to be measured and the methods used. CASEL (2020) provides a selection of assessment tools including self-report questionnaires, teacher and parent observation tools, rating scales, and performance assessments that can be used to inform and adapt further programming to ensure student needs are met. Future studies may also be needed to investigate a possible gender disparity in test-anxious students, and even potential program component effectiveness, given the higher proportion of female students self-selecting to participate in this study. A closer examination of the effects of SEL and mindfulness on other areas such as marginalized groups, the effect of teacher rapport, and a further understanding of its positioning within a Response to Intervention (RTI) framework (a scaffolded threetiered system providing supports targeting student needs) may also be warranted (Alberta Education, 2020). 


\section{Conclusion}

This study examined the effectiveness of SEL strategies and HM biofeedback on the reduction of test anxiety, emotional regulation, and academic performance. With up to $40 \%$ of adolescents experiencing anxiety leading to impairments in school performance (Bradley et al., 2010), it is incumbent upon educators to address this concerning trend and meet the students where they are. Students receiving this specialized SEL and study skills program significantly increased their self-efficacy, decreased their stress and worry, and improved their academic performance compared to a control group in regular programming. Many students were surprised that simply slowing down the breath would lead to calmer, more rational thinking, allowing them to prepare and execute tests with better attention and focus. Anecdotally, students commented that their test marks in other subjects had improved, and many described using HF breathing techniques beyond the classroom and in other areas of their lives such as music performances, speeches, and sporting competitions. Follow-up studies measuring SEL durability after program completion are limited (Durlak et al., 2011), as are standardized SEL skill metrics to determine which skills are currently being used and their overall effectiveness. Bridging the gap between developmental and educational research and teacher-led classroom practice of SEL and mindfulness is fundamental toward ensuring that practices are evidence-based and accountable. The addition of SEL practices into all curricula from K-12 may ultimately provide another tool for students to develop the social-emotional skills needed to navigate the ever changing and challenging world around them. 


\section{References}

Alberta Education. (2020). Response to intervention. https://education.alberta.ca/ media/464641/video-discussion-guide-9-rti.pdf

Aritzeta, A., Soroa, G., Balluerka, N., Muela, A., Gorostiaga, A., \& Aliri, J. (2017).

Reducing anxiety and improving academic performance through a biofeedback relaxation training program. Applied Psychophysiology and Biofeedback, 42(3), 193-202. https://doi.org/10.1007/s10484-017-9367-z

Auger, R. (2011). The school counselor's mental health sourcebook: Strategies to help students succeed. Corwin Press.

Ayalp, G., \& Özdemir, N. (2016). Relationship between test anxiety and learning styles of architecture undergraduates. Creative Education, 07(02), 364-375. https://doi. org/10.4236/ce.2016.72036

Bandura, A. (1994). Self-efficacy. In V. S. Ramachaudran (Ed.), Encyclopedia of human behavior (Vol. 4, pp. 71-81). Academic Press.

Bradley, R., McCraty, T., Atkinson, R., Tomasino, M., Daugherty, D., \& Arguelles, A. (2010). Emotion self-regulation, psychophysiological coherence, and test anxiety: Results from an experiment using electrophysiological measures. Applied Psychophysiology and Biofeedback, 35(4), 261-283. https://doi.org/10.1007/ s10484-010-9134-X

Bradshaw, C., Goldweber, A., Fishbein, D., \& Greenberg, M. (2012). Infusing developmental neuroscience into school-based preventive interventions: Implications and future directions. Journal of Adolescent Health, 51(2), S41-S47. https://doi.org/10.1016/j.jadohealth.2012.04.020

Christodoulou, G., \& Black, D. (2020). The utility of heart rate variability in mindfulness research. Mindfulness, 11(3), 554-570. https://doi.org/10.1007/ $\underline{\text { s12671-019-01296-3 }}$

Coelho, V., \& Sousa, A. (2017). Comparing two low middle school social and emotional learning program formats: A multilevel effectiveness study. Journal of Youth and Adolescence, 46(3), 656-667. https://doi.org/10.1007/s10964-016-0472-8 
Collaborative for Academic, Social, and Emotional Learning. (2020). What is SEL? https://casel.org/what-is-sel/

Corcoran, R. P., Cheung, A. C. K., Kim, E., \& Xie, C. (2018). Effective universal schoolbased social and emotional learning programs for improving academic achievement: A systematic review and meta-analysis of 50 years of research. Educational Research Review, 25, 56-72. https://doi.org/10.1016/j.edurev.2017.12.001

Cowley, P., \& Easton, S. (2018). Report card on Alberta's high schools 2018. Fraser Institute. https://www.fraserinstitute.org/sites/default/files/alberta-high-schoolrankings-2016.pdf

Creswell, J. W., \& Creswell, J. D. (2018). Research design: Qualitative, quantitative, and mixed methods approaches (5th ed.). SAGE Publications.

Domitrovich, C., Durlak, J., Staley, K., \& Weissberg, R. (2017). Social-emotional competence: An essential factor for promoting positive adjustment and reducing risk in school children. Child Development, 88(2), 408-416. https://srcdonlinelibrary-wiley-com.ezproxy.lib.ucalgary.ca/doi/full/10.1111/cdev.12739

Driedger, M. (2019, February 21-22). Understanding and alleviating assessment anxiety [Conference presentation]. Palliser Teacher's Convention, Calgary, AB, Canada.

Durlak, J., Weissberg, R., Dymnicki, A., Taylor, R., \& Schellinger, K. (2011). The impact of enhancing students' social and emotional learning: A meta-analysis of schoolbased universal interventions. Child Development, 82(1), 405-432. https://www. jstor.org/stable/29782838

Eklund, K., Kilpatrick, K. D., Kilgus, S. P., \& Haider, A. (2018). A systematic review of state-level social-emotional learning standards: Implications for practice and research. School Psychology Review, 47(3), 316-326. https://doi.org/10.17105/ $\underline{\text { SPR-2017.0116.V47-3 }}$

Gerwing, T. G., Rash, J. A., Allen Gerwing, A. M., Bramble, B., \& Landine, J. (2015). Perceptions and incidence of test anxiety. Canadian Journal for the Scholarship of Teaching and Learning, 6(3), 3. https://files.eric.ed.gov/fulltext/EJ1084598.pdf

Gill, P., Steward, K., Treasure, E., \& Chadwick, B. (2008). Methods of data collection in qualitative research: Interviews and focus groups. British Dental Journal, 204(6), 
291-295. https://www.nature.com/articles/bdj.2008.192?fbclid=IwAR3dnG9E1 kiF-kBEfvXjf1cvcxu-

HeartMath Institute. (2017a). How to use and score the student opinion survey.

HeartMath Institute. (2017b). Welcome to inner balance. https://cdn.heartmath.com/ manuals/inner balance ios_android.pdf

HeartMath Institute (2020). Inner Balance coherence sensor. https://www.heartmath.org/ store/products/inner-balance/

Jayanthi, M., \& Nelson, J. S. (2002). Savvy decision making. SAGE Publications. https:// doi.org/10.4135/9781412985765

Jones, S. M., \& Bouffard, S. M. (2012). Social and emotional learning in schools: From programs to strategies and commentaries. Social Policy Report, 26(4), 1-33. https://srcd.onlinelibrary.wiley.com/doi/pdf/10.1002/j.2379-3988.2012.tb00073.x

Keller, J., Ruthruff, E., Keller, P., Hoy, R., Gaspelin, N., \& Bertolini, K. (2017). "Your brain becomes a rainbow": Perceptions and traits of 4th-graders in a school-based mindfulness intervention. Journal of Research in Childhood Education, 31(4), 508-529. https://doi.org/10.1080/02568543.2017.1343212

Kross, E., \& Ayduk, O. (2011). Making meaning out of negative experiences by self-distancing. Current Directions in Psychological Science: A Journal of the American Psychological Society, 20(3), 187-191. https://doi. org/10.1177/0963721411408883

Lawlor, M. (2014). Mindfulness in practice: Considerations for implementation of mindfulness-based programming for adolescents in school contexts. New Directions for Youth Development, 2014(142), 83-95. https://doi-org.ezproxy.lib. ucalgary.ca/10.1002/yd.20098

McCraty, R., Atkinson, M., Tomasino, D., \& Bradley, R. T. (2006). The coherent heart: Heart brain interactions, psychophysiological coherence, and the emergence of system wide order (Publication No. 06-022). Institute of HeartMath. http://www. integral-review.org/issues/vol_5 no_2 mccraty_et_al the coherent heart.pdf

Meyer, D. (2016). Emotional regulation in K-12 classrooms. Taylor \& Francis. 
Nickerson, A., Fredrick, S., Allen, K., \& Jenkins, L. (2019). Social emotional learning (SEL) practices in schools: Effects on perceptions of bullying victimization. Journal of School Psychology, 73, 74-88. https://doi.org/10.1016/j.jsp.2019.03.002

Oberle, E., Domitrovich, C. E., Meyers, D. C., \& Weissberg, R. P. (2016). Establishing systemic social and emotional learning approaches in schools: A framework for schoolwide implementation. Cambridge Journal of Education, 46(3), 277-297. http://dx.doi.org/10.1080/0305764X.2015.1125450

O’Brien, R. G., \& Kaiser, M. K. (1985). MANOVA method for analyzing repeated measures designs: An extensive primer. Psychological Bulletin, 97(2), 316-333.

Polirstok, S. (2017). Strategies to improve academic achievement in secondary school students: Perspectives on grit and mindset. SAGE Open, 7(4), 2158244017745111. https://journals.sagepub.com/doi/pdf/10.1177/2158244017745111

Sasikala, S., \& Karunanidhi, S. (2010). Test anxiety in relation to behavioural problems of school students. Journal of Indian Academy of Applied Psychology, 5(1), 109-120. http://globalvisionpub.com/globaljournalmanager/pdf/1376976617.pdf

Seiden, D. (2020). Effects of a brief mindfulness curriculum on self-reported executive functioning and emotion regulation in Hong Kong adolescents. Mindfulness, 11(3), 627-642. https://doi.org/10.1007/s12671-019-01257-w

Smart Brain Wise Heart. (2020). Smart Brain Wise Heart eLearning program. https:// sbwh.heartmathelearning.org/sbwh/

Spielberger, C. D. (1980). Test anxiety inventory: Preliminary professional manual. Consulting Psychologists Press.

Spielberger, C. D., \& Vagg, P. R. (1987). The treatment of test anxiety: A transactional process model. In R. Schwarzer, H. M. Vander Ploeg, \& C. D. Spielberger (Eds.), Advances in test anxiety research (Vol. 5, pp. 179-186). Swets \& Zeitlinger.

Sullivan, G. M., \& Feinn, R. (2012). Using effect size - or why the P value is not enough. Journal Of Graduate Medical Education, 4(3), 279-282. https://doi.org/10.4300/ JGME-D-12-00156.1

Szafranski, D. D., Barrera, T. L., \& Norton, P. J. (2012). Test anxiety inventory: 30 years later. Anxiety, Stress \& Coping, 25(6), 667-677. https:/www.researchgate.net/ 
profile/Derek_Szafranski/publication/221879675_Test_Anxiety_Inventory_30 years later/links/5878fee508ae9275d4d90ab8/Test-Anxiety-Inventory-30-yearslater.pdf

Test Prep Review. (2020). Reading comprehension practice test 1 . https://www. testprepreview.com/modules/reading1.htm

Von der Embse, N., Barterian, J., \& Segool, N. (2013). Test anxiety interventions for children and adolescents: A systematic review of treatment studies from 2000-2010. Psychology in the Schools, 50(1), 57-71. https://doi-org.ezproxy.lib. ucalgary.ca/10.1002/pits. 21660

Von Der Embse, N., Jester, D., Roy, D., \& Post, J. (2018). Test anxiety effects, predictors, and correlates: A 30-year meta-analytic review. Journal of Affective Disorders, 227, 483-493. https://doi.org/10.1016/j.jad.2017.11.048

Walberg, H. J. (2013). Tests, testing, and genuine school reform. Hoover Press. https:// www.humbleisd.net/cms/lib/TX01001414/Centricity/Domain/5174/Testing\%20 -\%20For.pdf

Weems, C., Scott, B., Graham, R., Banks, R., Russell, J., Taylor, L., Cannon, M., Varela, R., Scheeringa, M., Perry, A., \& Marino, R. (2014). Fitting anxious emotionfocused intervention into the ecology of schools: Results from a test anxiety program evaluation. Prevention Science, 16(2), 200-210. https://link-springercom.ezproxy.lib.ucalgary.ca/article/10.1007/s11121-014-0491-1

Wilson, D. (2020). Practical meta-analysis effect size calculator. https:// campbellcollaboration.org/escalc/html/EffectSizeCalculator-SMD30.php

Wolf, L., \& Smith, J. (1995). The consequence of consequence: Motivation, anxiety, and test performance. Applied Measurement in Education, 8(3), 227-242. https://doi. org/10.1207/s15324818ame0803 3

Yeager, D. S., Romero, C., Paunesku, D., Hulleman, C. S., Schneider, B., Hinojosa, C., Lee, H. Y., O’Brien, J., Flint, K., Roberts, A., Trott, J., Greene, D., Walton, G. M., \& Dweck, C. S. (2016). Using design thinking to improve psychological interventions: The case of the growth mindset during the transition to high school. Journal of Educational Psychology, 108(3), 374-391. https://doi.org/10.1037/edu0000098

Zeidner, M. (1998). Test anxiety: The state of the art. Plenum Press. 